\title{
DOING AWAY WITH THE "SHMAGENCY" OBJECTION TO CONSTITUTIVISM
}

\section{Hille PaAKKunainen}

\author{
Syracuse University \\ Department of Philosophy \\ Syracuse, New York \\ U.S.A. \\ hpaakkun@syr.edu
}

\begin{abstract}
Article info
CDD: 128.1

\section{Keywords: \\ Constitutivism \\ Agency \\ Normative reasons \\ Shmagency}

Received: 01.09.2018; Accepted: 17.09.2018

DOI: http://dx.doi.org/10.1590/0100-6045.2018.V41N4.HP

\begin{abstract}
Constitutivists attempt to ground reasons for action in the constitutive features of agency. Central to Enoch's famous "shmagency" objection to constitutivism is the idea that constitutivists should worry about the question whether there is reason to be an agent rather than a "shmagent"-where a shmagent is a non-agent being who lacks the constitutive features of agency, but is otherwise as similar to agents as can be. I explain why constitutivism isn't in trouble even if there's no reason to be an agent. The nature of agency can in principle ground authoritative reasons for agents to act, even if there isn't, in addition, a reason to be an agent. Relatedly, I explain why a prominent strand in previous responses to Enoch is misleading in focusing on whether the request for reasons to be an agent, as posed by the shmagent, is even possible or intelligible. Even if the shmagent's request for reasons is possible and intelligible_-as I argue it is - this doesn't matter for constitutivists, for the request is misguided: constitutivists need no reasons to be an agent.
\end{abstract}


Constitutivists hold that authoritative practical normsand most importantly, normative reasons for action-are grounded in the constitutive features of agency. Constitutivists differ in their views about the substance of the reasons and norms that agency grounds, depending on their views about the nature of agency itself. The most ambitious constitutivists hold that agency grounds authoritative norms with recognizably moral import. ${ }^{1}$ For less ambitious constitutivists, agency grounds only nonmoral norms, such as reasons or requirements to take the means to one's ends. ${ }^{2}$ Still, constitutivists are united in holding that the constitutive features of agency ground authoritative practical norms. A different way to align agency with norms would be to hold that it's in the nature of agency to somehow track or respond to independently existing authoritative norms. Such tracking views can allow that examining agency yields epistemic insight into the content of those norms. But unlike constitutivism, tracking views don't purport to ground authoritative norms in the nature of agency. ${ }^{3}$

David Enoch (2006, 2011a) famously objects to the very idea of constitutivism by arguing that, whatever the nature of agency, we cannot ground authoritative practical norms in it - at least, not without presupposing a non-constitutivist element that dooms constitutivism's prospects as a foundational theory of normativity. While many constitutivists and their allies have responded (Velleman

\footnotetext{
${ }^{1}$ Korsgaard 1996, 2009, Walden 2012, Smith 2013, 2015.

2 Dreier 1997/2001; cf. Vogler 2002. For Velleman 2009, agency grounds a norm demanding the pursuit of self-understanding, where such pursuit needn't amount to a recognizably moral life.

${ }^{3}$ See Raz (1999a) for a prominent tracking view. For Setiya 2007, both constitutivism and tracking views are forms of 'ethical rationalism' that require false views about agency.
} 
2009, Ferrero 2009 and 2018, Katsafanas 2013, O'Hagan 2014, Silverstein 2015, Smith 2015), I don't think the extant responses have adequately explained what's wrong with Enoch's objection. In particular, none of the extant responses clearly enough challenge a central claim of Enoch's: namely, that constitutivists should worry about the question whether there is reason to be an agent (rather than a "shmagent" - a non-agent being who lacks the constitutive features of agency in which constitutivists attempt to ground reasons, but is otherwise as similar to agents as can be). As against both Enoch and extant responses to him, I explain why constitutivism isn't in trouble even if there's no reason to be an agent whatsoever. The nature of agency can in principle ground authoritative reasons for agents to act, even if there isn't, in addition, a reason to be an agent. Relatedly, I explain why many extant discussions have been wrong to focus on the question whether the request for reasons to be an agent is even possible or intelligible-specifically, whether it can be intelligibly raised from a perspective outside of agency (such as that of "shmagency"). Even if the request for reasons to be an agent is intelligible, and can be intelligibly made by some non-agent being, this isn't a problem for constitutivism. I thus seek to move the debate away from the question of intelligibility.

Of course, dispelling Enoch's objection in this way, and redirecting the debate, isn't yet to argue, positively, that any particular constitutivist view actually succeeds in grounding reasons for action in the nature of agency. Still, I'll also briefly sketch a way in which I think such a grounding would succeed, provided certain assumptions about the nature of agency. This positive proposal is merely a sketch: at most a proof of concept, and by no means a thorough argument for constitutivism. But it will help in seeing even more clearly why the success of the constitutivist project of grounding reasons in agency doesn't depend on the question whether there's reason to "be an agent." 
$\$ 1$ explicates the structure of constitutivism in more detail and introduces Enoch's objection. \$2 explains why Enoch's request for a reason to "be an agent" isn't a request that constitutivists need to worry about, and explains why this dissolves Enoch's objection. \$3 discusses previous responses to Enoch in light of my argument in \$2, explaining where they go wrong (or where they don't go far enough), and seeking to redirect the debate onto more fertile ground. \4 then sketches my positive suggestion as to how constitutivists could, in principle, ground normative reasons for action in the nature of agency, provided certain premises about the nature of agency. $₫ 5$ concludes.

\section{The STRUCTURE OF CONSTITUTIVISM AND ENOCH'S OBJECTION}

It will be helpful to appreciate the general structure of constitutivist views about agency. Constitutivists hold that agency has constitutive standards or aims: standards or aims that are somehow constitutive of the nature of agency, or stem in some explicable way from the constitutive features of agency; and that are also the measure of which exercises of agency are good or bad qua such exercises. For Velleman (2009), for example, agency has the constitutive aim of selfunderstanding, in the sense that all exercises of agency must aim at self-understanding on pain of failing to be exercises of agency at all (2009:133-135). Velleman explicates the relevant sort of "aiming" in terms of a desire or "drive" for self-understanding that is operative in every exercise of agency just as such, influencing "which desired objects we choose to pursue, how we harmonize them with one another, [and] organize our efforts toward them" (2009:28). This drive disposes agents to act on considerations that are indicators of "intelligibility" to self: on considerations, and 
in ways, that allow, to varying degrees, the agent to understand what she herself is up to in so acting (2009:133). It's not that every exercise of agency results in perfect selfunderstanding; but every exercise of agency must stem partly from this drive for self-understanding, which shapes the agent's response to her other desires. And if A's $\Phi$-ing on the basis of the consideration that $p$ (or as I'll say, A's $\Phi$-ing because $p$ ) conduces to A's self-understanding more than would A's $\Phi$-ing because $q$ or A's $\Psi$-ing because $p$, then A's $\Phi$-ing because $p$ is better qua exercise of agency than either of these other options would be.

Other constitutivists hold structurally similar views. For Korsgaard (2009), agency is a matter of being "guided" by Kantian categorical and hypothetical imperatives, in the sense that agents as such are disposed to deliberate and, as a conclusion of deliberation, act, in accord with those imperatives; and to exercise agency is to manifest these dispositions, at least to some degree. Here agency's constitutive standards are the categorical and hypothetical imperatives. The more perfectly one's actions and deliberations accord with these imperatives, the better they are qua exercises of agency. ${ }^{4}$ For Dreier (1997/2001), agency is a matter of manifesting a disposition to deliberate in accord with an instrumental rule telling you to take the acknowledged means to your desired ends. Here the constitutive standard of agency is the relevant instrumental rule.

Smith (2015) formulates his view in terms of "functions," holding that agency has the function of desire-realization: agents as such are desire-realizers, and to be good (bad) qua agent is to perform this function well (badly). Specific capacities are needed to perform this function optimally well:

4 See esp. 2009:chs.2-4. The precise formulations of the imperatives don't matter here. 
the capacity to reliably form true beliefs about means to desired ends (across a range of circumstances), and the capacity to be locally and globally instrumentally rational (2015:189-190). Having and fully exercising these capacities makes one better qua a desire-realizer (qua an agent) than one would otherwise be. Smith also holds that optimally functioning agents have specific coherence-inducing desires that dispose one towards recognizably pro-moral actions (2015:190-192). One is worse qua agent if one lacks these desires or if they fail to be effective, better if one has them and they are effective.

There may be interesting differences between talk of "functions" and talk of "constitutive standards or aims," but we needn't worry about them in the present context. We might describe Smith as holding that desire-realization is agency's basic constitutive standard or aim; and the standards of local and global instrumental efficacy, and so on, are subsidiary standards that one must satisfy in order to optimally satisfy the basic standard of desire-realization. For present purposes, the key point of interest about constitutive standards or functions is their evaluative role: they ground evaluative facts about which exercises of agency are good or bad qua such exercises. More carefully, they ground such evaluative facts together with the following general fact about a form of evaluation:

Attributive Goodness: What it is for a member of kind K, $k 1$, to be good (bad) qua a $\mathrm{K}$, is for $k 1$ to conform well (badly) to the constitutive standards of Ks [or to perform well (badly) the "function" of Ks]. 5

${ }^{5}$ Geach 1956; cf. Korsgaard 2009:ch.2, Smith 2015:189. 
To illustrate how familiar the ideas of constitutive standards and related evaluations are, constitutivists often draw an analogy with games such as chess, which also have constitutive standards. The constitutive standards of chess are the rules defining legal moves, such as "the bishop moves diagonally," together with the constitutive aim of checkmating the opponent. These standards are constitutive of the nature of the game: different standards, different (version of the) game. ${ }^{6}$ And the constitutive standards, together with Attributive Goodness, ground facts about which ways of moving the pieces are good or bad qua chess moves. Roughly, a move is better qua a chess move the closer it gets its maker to achieving the constitutive aim of chess, and worse qua a chess move the further it takes its maker from that aim. A move that fails to even be chess-legal is not a chess move at all.

Agency's constitutive standards are supposed to be roughly analogous. Of course, the relation that agency's constitutive standards bear to exercises of agency is in some ways different from the relation that the constitutive standards of chess bear to chess moves. For example, the game of chess, or a specific chess set, don't themselves make chess moves, whether good or bad; agents do. In contrast, agents themselves exercise their agency, thereby satisfying or failing to satisfy agency's constitutive standards to various degrees. There may be further asymmetries. For instance, chess and its rules are undeniably social constructs, whereas it's controversial whether agency and its constitutive

\footnotetext{
${ }^{6}$ Arguably we may change the rules of a game slightly without changing which game it is. It's an interesting question whether the constitutive norms of agency could likewise change slightly without changing their being constitutive of agency. I set aside this question about the nature of agency here.
} 
standards are. $^{7}$ Still, constitutivists needn't claim that everything that has constitutive standards relates to those standards in exactly the same way. The important point for our purposes is that the structure of evaluation is kept intact: like the constitutive standards of chess, agency's constitutive standards ground evaluative facts to the effect that particular exercises of agency are good or bad qua such exercises. An exercise of agency is better (worse), qua such an exercise, the more (less) closely it approximates to perfectly satisfying agency's constitutive standards-whatever exactly these standards are, and however exactly they are implicated in the metaphysics of agency. ${ }^{8}$

How then might we ground authoritative norms, and in particular, normative reasons for action, in facts about agency, supposing agency does have constitutive standards? As we've seen, agency's constitutive standards seem to ground, in the first instance, attributive evaluations - of forms such as these:

Acting-for-reasons Atrributive: A's $\Phi$-ing for the reason that $p$ (A's $\Phi$-ing because $p$ ) in circumstance $C$ is good qua exercise of agency in $\mathrm{C}$.

\footnotetext{
${ }^{7}$ For Walden 2012, which standards are constitutive of agency is a partly social matter, a matter of which dispositions and capacities agents must have and manifest to be interpretable as agents by relevant others. Other constitutivists, such as Korsgaard 2009 and Smith 2013, 2015, incorporate no such social element.

8 Velleman talks of actions as (more or less) "correct" or "apt" qua actions (2009:122, n.9). Katsafanas 2013 talks of standards of "success" for actions. I'll stick with good/bad qua actions. Perhaps, to be a $\mathrm{K}$ at all, $k 1$ must achieve a threshold of success in meeting the constitutive standards of Ks; but see Lindeman 2017 for a critique of this idea.
} 
Deliberation Attributive: A's deliberation is better qua exercise of agency the more perfectly it accords with inference rule(s) $R$.

But prima facie, this is not yet to ground facts of the following form:

Normative reasons: The fact that $p$ is a normative reason for A to $\Phi$ in circumstance $C$.

Yet constitutivists typically wish to ground normative reasons, not just attributive evaluations, in the constitutive features of agency. ${ }^{9}$ This brings us to Enoch's objection. Enoch concedes that agency might have constitutive standards; and, I take it, that these standards might ground facts about which exercises of agency are good or bad qua such exercises. What Enoch doubts is that agents thereby genuinely should do, or have any genuine reason to do, what they would do if they deliberated and acted well qua agent. Consider chess again. Its constitutive standards determine a move's goodness qua a chess move. But it doesn't follow that I genuinely ought to, or have any genuine reason to, make good chess moves, or to play chess at all. Not even if I'm already playing, and not even if I can't stop! Suppose I make up a game of stealing food from children, complete with constitutive standards that determine what it is to do well at this game; and now I can't stop playing it. These facts don't seem to give rise to any normative reasons for me to steal the food. Instead — and this is the crucial point — in order for there to be a reason for me to steal the food, it seems that I

9 The ambition to ground reasons in agency is clear in e.g. Katsafanas 2013, Velleman 2009, Dreier 1997/2001, Korsgaard 1996, Smith 2015. The issue is less clear in Walden 2012; and Korsgaard's 2009 attitude to "reasons" talk is complicated. 
need some prior, independent reason to obey the constitutive standards of the game. ${ }^{10}$

Enoch puts the general point by saying that a standard S's being constitutive of some enterprise $\mathrm{E}$ doesn't give $\mathrm{S}$ "normatively non-arbitrary status" (2011a:209). And if this is right about enterprises in general, Enoch thinks, then it also applies to the enterprise of agency. Like the constitutive standards of other enterprises, agency's constitutive standards are worth heeding or obeying only given some antecedent reason to do so. ${ }^{11} \mathrm{It}$ 's natural to put the point in terms of normative authority. Like the constitutive standards of games, agency's constitutive standards either have no genuine authority over our actions, or at best inherit their authority from some prior normative reasons to abide by them..$^{12}$ In and of themselves, agency's constitutive standards are just as normatively unimportant as are the standards of made-up games.

Enoch dramatizes this objection by means of the figure of a "shmagent." Shmagents are supposed to be non-agent beings who don't "care" about being agents, or about performing actions, and are happy performing "shmactions" instead- "nonaction events that are [as similar to] actions [as can be]" without having the constitutive standards of action

10 Enoch 2011a:209-211; 2006:178-180, 185; the food-stealing game example is mine.

11 Ibid.

12 Such inherited authority is in one sense "hypothetical": authority only given some further reason to abide by the standard. In another sense, norms or standards are "hypothetically" authoritative when their authority on an agent depends on her contingent inclinations. It's not usually noted that these two notions cut across one another. 
or agency (2006:179). ${ }^{13}$ Shmagents can ask why they should be agents, or obey agency's constitutive standards - where this question is a request for normative reasons. And just as pointing to the constitutive-of-chess status of the standards of chess is insufficient to show that one has any genuine reason to move the pieces in accord with these standards, likewise pointing to the constitutive-of-agency status of agency's constitutive standards is insufficient to answer the shmagent's question. So the objection goes; and again, Enoch concludes that agency's constitutive standards at best inherit their authority from some antecedent reason to heed them-from a reason to "be an agent."

If this is right, it's very bad news for constitutivism. There might of course be some prior, independent reasons to heed agency's constitutive standards. ${ }^{14}$ But the point is that appeal to such reasons would abandon constitutivists' ambitions to give "the whole, or the most foundational, account of normativity" (Enoch 2011a:209). If agency's constitutive standards at best inherit their authority from prior and independent normative reasons to heed them, then the fundamental truth about what makes these standards authoritative, and why we have reason to do what it would be good qua agent to do, is non-constitutivist.

$\$ 2$ presents my core response to this objection on behalf of the constitutivist. In short, constitutivists don't need a reason to "be an agent" in order to be able to ground other reasons-reasons for all the things that us agents have reasons to do-in the nature of agency. Accordingly, agency's constitutive standards needn't either inherit their authority from some external source, or else lack authority altogether. Instead, agency's constitutive standards are

13 See 2011a:209, 214 n.17 for the "as similar ... as can be" qualification.

${ }^{14}$ Enoch 2011a:227.

Manuscrito - Rev. Int. Fil. Campinas, v. 41, n. 4, pp. 431-480, Oct-Dec. 2018. 
authoritative in and of themselves if, and because, they themselves ground reasons to do what it would be good by the lights of those very standards (good qua exercise of agency) to do. Of course, this leaves in place a crucial explanatory task for constitutivists: to explain precisely how the alleged grounding of reasons goes (I sketch a way in \$4). But Enoch's “shmagency" objection doesn't present any positive reason to think that this explanatory task can't be discharged.

\section{REASONS TO "BE AN AGENT" ARE IRRELEVANT TO THE TASK OF GROUNDING REASONS IN AGENCY}

Suppose the request for reasons to be an agent, or to obey agency's constitutive standards, is possible and intelligible. ${ }^{15}$ Even so, it may be misguided in the dialectical context: perhaps it doesn't matter for the prospects of constitutivism whether or not there are reasons to be an agent. As I'll now argue, this is the case. Whether or not constitutivists succeed in grounding reasons for action in the constitutive features of agency doesn't depend on whether there's any reason to be an agent. Even if there's no reason to be an agent, the other reasons the constitutivist grounds may all still be in good order. And even if there is also a reason to be an agent, this

\footnotetext{
${ }^{15}$ Ferrero 2009 and 2018 argues that the request isn't even possible when it's understood "externally" — where an "external" request is one made from outside of the "enterprise" of agency, or while not engaged in agency. The point is to argue that the "shmagent" couldn't raise the supposedly troublesome question about reasons to be an agent. Similarly, Velleman 2009 argues that the shmagent's request for reasons to be an agent-at least, understood as a request for reasons that obtain independently of agency's constitutive standards - is unintelligible. I explain in \$3 why this style of response to Enoch doesn't go far enough; and is, in any case, probably mistaken.
} 
additional reason wouldn't help the constitutivist in her fundamental task anyway-in showing how to ground reasons in facts about the constitution of agency.

Start with the possibility that there is a reason to be an agent. This reason is either itself constitutivist—grounded in the constitutive features of agency-or it's not. If it's not, then its existence clearly wouldn't help constitutivism in the task of giving a foundational story about normativity by grounding reasons in agency. As Enoch notes, appealing to reasons to be an agent that obtain independently of the nature of agency would belie constitutivists' ambitions to give the foundational story about normativity. ${ }^{16}$ On the other hand, if the supposed reason to be an agent is a constitutivist one, then it must have been grounded somehow in the constitutive features of agency-presumably, in a way similar to that in which, according to the constitutivist, reasons for action are grounded in the first place. So the constitutivist owes us precisely the kind of story about the grounding of this reason to be an agent, as she owes about reasons more generally: she owes us an explanation of how the alleged grounding goes. (I sketch a possible way to ground reasons for action in agency in \$4.) Either way, the existence of a reason to be an agent wouldn't help the constitutivist in her task. ${ }^{17}$

${ }^{16}$ Enoch 2011a:209; and see the discussion in $₫ 1$ above.

17 Would it hinder the constitutivist? If the reason to be an agent were itself a constitutivist one, then presumably not. If the reason to be an agent were a non-constitutivist one, then it might-at least, if constitutivism purports not just to ground some reasons in agency but also to be the correct story about where all of our reasons come from. Still, Enoch's objection isn't that there's a nonconstitutivist reason to be an agent. And in any case, merely asserting that there is such a reason would simply beg the question against those constitutivists who wish to give a story about all of our reasons: it wouldn't constitute an effective objection. 
What, then, about the possibility that there's no reason to be an agent, or to obey agency's constitutive standards? Recall that the constitutivist primarily tries to ground reasons for action in the constitutive standards of agency. She owes us a story about how the constitutive standards of agency make it the case not only that an agent A's $\Phi$-ing because $p$, in circumstance $\mathrm{C}$, is good qua exercise of agency, but also why $p$ is, in $\mathrm{C}$, a normative reason for $\mathrm{A}$ to $\Phi$. Would it hinder the constitutivist's prospects of successfully giving such a story, if there were no reasons to obey agency's constitutive standards? That is, would agency's constitutive standards be unable to ground particular reasons for action, if we didn't, in addition, have some kind of explanatorily prior reasons to obey those standards? I don't see why this would have to be so. Even if there's no reason to "be an agent," in the sense of having some prior reason to obey agency's constitutive standards, the other reasons that the constitutivist purports to ground in the constitutive standards of agency could all still be in good order. Further, if the presence of a reason to be an agent wouldn't help the constitutivist in her fundamental task of showing how to ground reasons in agency-as I argued above- then it's hard to see why the absence of a reason to be an agent would hinder that task.

If this doesn't seem obvious, it may help to make a general point about grounding, by means of two examples.

Example 1: Grounding the fact that objects X1...X100 are red

The fact that particular objects X1...X100 are red can be grounded in the various surface-reflectance properties of $\mathrm{X} 1 \ldots \mathrm{X} 100$, perhaps together with certain properties of typical viewers, without any need to show that these various surface-reflectance properties or properties of viewers are in turn 
grounded in redness, or in red things; and indeed without any need to show that there are also certain further objects, $\mathrm{Y}$, that are red, and whose redness helps to explain why X1...X100 are red. X1...X100 might be the only red objects in the world. In order for X1...X100 to be red, and in order for the fact that $\mathrm{X} 1 \ldots \mathrm{X} 100$ are red to be grounded in something, it needn't be "red things all the way down"; nor need there be more red things than $\mathrm{X} 1 \ldots \mathrm{X} 100$.

Example 2: Grounding the fact that objects X1 ..X100 are spherical

Likewise, the fact that particular objects X1...X100 are spherical can be grounded in various facts about the arrangements of their constituent particles and properties, without any need to show that these constituent particles and properties are in turn grounded in sphericality, or in spherical things; and indeed without any need to show that there are also certain further objects, Y, that are spherical, and whose sphericality helps to explain why X1...X100 are spherical. X1...X100 might be the only spherical objects in the world. In order for there to be spherical objects, and in order for the fact that $\mathrm{X} 1 \ldots \mathrm{X} 100$ are spherical to be grounded in something, it needn't be "spherical things all the way down"; nor need there be more spherical things than $\mathrm{X} 1 \ldots \mathrm{X} 100$.

I hope it's clear that we could multiply examples. The general lesson here is that, at least for a great many properties $\mathrm{F}$, the fact that some objects X1...X100 have F can be grounded in something, without being grounded in further objects that themselves have F, and indeed without there even existing any further objects that are F. I don't rule out 
the possibility of some properties for which this general lesson fails to hold. But it's quite difficult to see what those exceptional properties might be. At any rate, it's not clear why the property of being a normative reason (for some response) would be an exception to the general lesson. If it is an exception, then anti-constitutivists should spell out why. ${ }^{18}$ In the meanwhile, we can assume that it isn't, and constitutivists can claim the following:

Example 3: Grounding the fact that considerations $p 1 \ldots p 100$ are normative reasons

The fact that particular considerations, p1...p100, are normative reasons for some responses (for some agents) can be grounded in facts about the constitutive standards of agency, without any need to show that these facts about constitutive standards are in turn grounded in reasons, or in something's being a reason; and indeed without any need to show that there are also certain further considerations, $\mathrm{q}$, that are reasons for anything, and whose being a reason helps to explain why p1...p100 are reasons. p1...p100 might be the only normative reasons there are. In order for there to be

\footnotetext{
${ }^{18}$ Of course, some have general doubts about whether facts about normative reasons could possibly be grounded in anything that's not similarly normative-doubts that are expressed, for example, in the intuition that the normative is "just too different" from the non-normative to be fully grounded in it or reducible to it (see e.g. Enoch 2011b:80, 104-9 for this idea; but see Paakkunainen 2018 for critical discussion). However, Enoch doesn't present his "shmagency" objection as being just a version of this general doubt. Further, if the general doubt were the real objection here, then the objector should simply press the general doubt; and it would still be unclear why the question about reasons to be an agent, in particular, is pertinent to the success of constitutivism.
} 
normative reasons, and in order for the fact that p1...p100 are normative reasons to be grounded in something, it needn't be "reasons all the way down"; nor need there be more reasons than p1...p100.

In particular, if $p 1 \ldots p 100$ are reasons for action grounded in the constitutive standards of agency, there needn't be any further reasons, $q$, for some further response of "being an agent" or "obeying agency's constitutive standards," whatever that response might consist in.

To clarify, I don't mean the above argument to show that constitutivists can, indeed, ground reasons in the constitutive standards of agency. Clearly it shows no such thing. The point is rather that, as far as the nature of grounding goes, there's generally no requirement that, in order for some facts to ground something's having property F, something else has to have property $\mathrm{F}$ as well. And prima facie, the case is no different when $\mathrm{F}$ is the property of being a normative reason. Whether any constitutivist actually succeeds in grounding reasons for action in the constitutive standards of agency is a further question. Again, I briefly consider how such a grounding might go (without appeal to prior reasons to "be an agent") in $\$ 4$.

If the foregoing is right, then whether or not constitutivists succeed in grounding reasons for action in the constitutive features of agency doesn't depend on whether there's any reason to be an agent. In sum: Even if there's no reason to be an agent, the other reasons the constitutivist grounds may all still be in good order. On the other hand, even if there is a reason to be an agent, this additional reason wouldn't help the constitutivist in her fundamental task anyway - the task of showing how to ground reasons in facts about the constitution of agency. And if the presence of a reason to be an agent wouldn't help the constitutivist in her task of grounding reasons in agency, then it's hard to see why the absence of a reason to be an agent would hinder her in 
that task. At any rate, as I argued, there's nothing in the nature of grounding explanations generally that suggests that constitutivists would be hindered by the absence of a reason to be an agent.

Why then might it have seemed so plausible, as per Enoch's "shmagency" objection, that agency's constitutive standards couldn't possibly ground reasons to act in accord with them, without a prior reason to be an agent? I offer two suggestions by way of diagnosis.

First, in the case of games such as chess, it does seem quite compelling that that the mere fact that, say, moving the bishop two squares diagonally would be good qua a chess move, doesn't show that one has any normative reason to make that move. Perhaps one isn't interested in playing chess at all, and a better use for the pieces would be to use them as firewood. Further, as Enoch notes, even if one is in fact playing - and even if one can't stop-it still seems doubtful that one thereby has any real reason to make the move; witness, again, the possibility of malicious games that one can't stop playing. It does seem plausible, then, that the constitutive standards of games don't ground genuine normative reasons to act in accord with those standards, even as they ground attributive evaluations of certain actions as good qua moves in the game. It also seems quite plausible that the only way in which one would have reasons to make the relevant moves would be if one had some prior reason to play the game in question. ${ }^{19}$ Generalizing from the case of

${ }^{19}$ One might resist these conclusions even in the case of games: perhaps playing a game involves having an aim, and perhaps merely having an aim is enough to generate pro tanto reasons for actions that would promote that aim. Appeal to the "subjectivist" idea that having an aim generates reasons is one way to resist Enoch's argument, and indeed one way in which constitutivists might develop their positive view. Like every aim, agency's constitutive aim would generate reasons, but such reasons would be "universal" in the sense of applying to all agents regardless of their contingent 
games, we might conclude that the constitutive standards of all enterprises, agency included, are in the same boat.

However, Enoch hasn't actually given us any positive reason to think that agency's constitutive standards must be in the same boat as the constitutive standards of other enterprises. In his "Shmagency Revisited," Enoch in effect concedes this point (2011a:211). What constitutivists do owe us is an explanation of why and how agency and its constitutive standards are different from games and their standards, such that agency's constitutive standards ground not just attributive evaluations but also genuine normative reasons to act in accord with them. The relevant explanation should spell out precisely how agency's constitutive standards generate reasons. But this is, in effect, just the burden of explaining how the constitutivist's positive foundational theory of normativity works. This is a burden that constitutivists face anyway, regardless of Enoch's objection. (Again, $\$ 4$ considers how constitutivists might discharge the explanatory burden.) What I've been stressing is that constitutivists needn't worry that part of the

aims or inclinations. See Katsafanas 2013, 2018 for such a constitutivist view; cf. e.g. Schroeder 2007 for a sophisticated nonconstitutivist development of the subjectivist idea. As a response to Enoch's objection, though, the appeal to subjectivism involves a large commitment that not all constitutivists will be happy with. It's better to have a response to Enoch's objection, such as mine, that more constitutivists can accept. Moreover, the appeal to subjectivism makes constitutivism just a version of another, independent type of metanormative theory; and if all aims generate reasons, there will presumably be many reasons that have nothing to do with the constitutive aim of agency. Such views are still of interest, of course, but most constitutivists seem to hope to show how constitutive aims or standards have a more central and distinctive kind of metanormative import. 
grounding story must be an appeal to a "reason to be an agent." 20

So the first diagnostic suggestion is that the game analogy is potentially misleading at precisely the crucial juncture of explaining how normative reasons could be generated by the constitutive standards of agency. Constitutivists have the burden of proof in showing that the game analogy is indeed misleading here, but it's a burden that they in effect face anyway - the burden of explaining how their positive view works. Enoch's objection adds no new hurdle for constitutivists.

The second diagnostic suggestion concerns the initial dialectical context in which Enoch formulated his shmagency objection. In his (2006) "Agency, Shmagency: Why Normativity Won't Come from What is Constitutive of Action," Enoch formulates his objection against the

${ }^{20}$ We might think that Enoch's objection does show_due to the example of games-that constitutive standards alone cannot ground reasons for action: that something in addition is needed. And while a tempting "addition" would be a further reason to heed those constitutive standards, constitutivists need to find some different candidate "addition" in order for their view to succeed. Perhaps this adds to the constitutivist's explanatory burden, beyond what they faced anyway prior to Enoch's objection. (Thanks for David Horst for this suggestion.) However, constitutivists never claimed that all constitutive standards, just as such, ground reasons for action: their claim was all along that it's the constitutive standards of agency in particular that ground such reasons. To be sure, as I say in the text, constitutivists should explain precisely how agency's constitutive standards manage to ground reasons for action, where other constitutive standards fail. But this explanation needn't take the form of finding some "addition" that helps agency's constitutive standards to ground reasons. It can instead take the form of explaining what the link is between reasons for action and agency's constitutive standards (a link that is absent between reasons and other constitutive standards). 
background of a concern with answering skeptical questions to the skeptic's satisfaction. This is partly because his main foils in formulating the objection are Rosati (2003) and Korsgaard (2009), each of whom subscribes to a version of the view that true normative demands are such as to leave no room for plausible, clear-eyed, well-informed skepticism about whether they obtain. ${ }^{21}$ Enoch then argues that it certainly seems as if one can raise a plausible skeptical question about putative reasons grounded in agency's constitutive standards, even while one has all the relevant information and is thinking clearly. One can doubt whether one has any real reason to do what it would be good by the lights of agency's constitutive standards to do. And merely pointing out that, unlike the rules of games, the relevant standards are constitutive of agency, so that one wouldn't even be an agent if one didn't heed them to some extent, doesn't seem to quiet the possibility of such skepticism. For one can push the skeptical question back a step and ask: "Why be an agent?" Hence the seeming relevance of the question whether one has any reason to be an agent.

However accurate this might be as a diagnostic suggestion, it's not clear that constitutivists as such must regard their views as leaving no room for plausible, wellinformed skeptical questions. For one thing, constitutivists are trying to give a philosophical theory of how to ground reasons in the constitutive features of agency; and like most philosophical theories, the arguments get intricate, and won't win over all well-informed philosophers, who may themselves hold other, plausible competing views. It's not clear why constitutivist arguments_-or anyone's arguments, for that matter-should be held up to the standard of leaving

${ }^{21}$ For a more careful discussion of Rosati's and Korsgaard's views in this regard, see Paakkunainen 2017a. Note that subscribing to the view just described in the text doesn't yet make one a constitutivist; cf. Rosati 2016. 
no room for plausible, well-informed skepticism. After all, most philosophical theories are subject to substantial amounts of peer disagreement. ${ }^{22}$ For another thing, even if Enoch's "shmagent" retains a plausible skepticism in the face of the simple retort that agency's constitutive standards are, after all, constitutive of agency, this simple retort falls far short of a full explanation of how the constitutivist is supposed to ground reasons in the standards of agency. And it may be that, given such a full explanation-if the explanation is sufficiently good-most skeptical questions would subside. At least, if the constitutivist's positive theory is any good, and the "shmagent" is fully informed of that theory, then she should come to see it as more plausible how agency's constitutive standards might indeed ground normative reasons for action.

Either way, the point remains that the constitutivist needn't really worry about the question "why be an agent," understood as a request for reasons to be an agent, or to obey agency's constitutive standards. All that the constitutivist needs to worry about is giving a clear articulation of precisely how the feat of grounding reasons for action in the constitutive standards of agency is supposed to go. (Again, I sketch a way in \$4.) Given such a philosophical argument for her view, there may or may not be room left for wellinformed, plausible skepticism. But even if there is, there's no good reason to think that that's especially worrisome for constitutivism. ${ }^{23}$

\footnotetext{
22 On this point, see e.g. Kornblith 2010.

23 At least, there's no good reason to think that it's especially worrisome for constitutivism as such. There are certain varieties of constitutivism, or ways of arguing for constitutivism, that may face trouble. Specifically, Korsgaard's conception of normative reasons in her (1996) Sources of Normativity is that of a kind of reflective success: something is a reason for you to act if, but only if, and because, you would deem it to be a reason after clear-eyed, well-
} 
In this section, I've argued that the success of constitutivists' project of grounding reasons for action in the nature of agency doesn't depend on whether there are reasons to "be an agent." I then offered two diagnostic suggestions regarding why the shmagent's request for reasons to be an agent may have seemed pertinent, explaining in each case why the appearance of pertinence is ultimately misleading.

I hope it's clear why the foregoing dissolves Enoch's objection. The core of Enoch's objection was that, like the constitutive standards of other enterprises, agency's constitutive standards are such that we have genuine reason to do what's good by the lights of these standards only if we have some antecedent reason to obey them-a reason to "be an agent." The core of my response is that constitutivists needn't, and shouldn't, worry about reasons to "be an agent." So long as constitutivists can explain how agency's constitutive standards ground reasons for action-in particular, how they ground reasons to do what it's good qua agent to do- then they have an explanation of why we have reason to do what's good by the lights of agency's constitutive standards. No extra reasons to "be an agent" are needed here. This would also constitute an explanation of

informed, and specifically skeptical reflection (1996:93-94). Such reflection, according to Korsgaard, takes place against the background of your various commitments or "practical identities"; but as the reflective agent pushes back the skeptical "normative question" of whether something really is a reason, she eventually comes up against her identity simply as a rational agent-her "humanity" in the Kantian sense. And here Korsgaard seems to think that it doesn't even make sense to doubt whether one's identity as a rational agent is reason-giving (1996:121-4). This particular view may be in trouble if, as Enoch claims, it's possible or intelligible to ask "why be a [rational] agent"? Still, as I've argued, the project of grounding reasons in agency isn't in trouble, just as such. 
why agency's constitutive standards have a kind of uninherited authority that the constitutive standards of games lack. While the standards of games at best inherit their authority from prior normative reasons to abide by them, the standards of agency are authoritative in and of themselves: they themselves ground reasons to act in accord with themselves. Of course, whether the constitutivist's story about grounding reasons succeeds is a large and unresolved question. Again, I sketch a possible way to ground reasons for action in agency (sans reasons to "be an agent") in $\$ 4$. The present point is that Enoch's "shmagency" objection gives us no positive reason to think that the constitutivist's grounding task won't succeed.

\section{WHERE EXTANT RESPONSES TO ENOCH GO WRONG}

Armed with the insight that constitutivists needn't worry about reasons to "be an agent," we can clarify where a prominent strand of responses to Enoch goes awry, and thereby redirect the debate onto more fertile ground. I start with Luca Ferrero.

\subsection{FERRERO}

Ferrero's response to Enoch's shmagency objection takes the form of arguing that, when the request for reasons for "be an agent" is understood as an "external" question, in the sense that it's putatively asked while not exercising agency, but rather something else, such as "shmagency", it's impossible (2009:308-12; 2018, \$3.3). Shmagents-nonagent beings - cannot request reasons to be an agent. This is because, according to Ferrero, the activity of giving and asking for practical reasons is itself, inescapably, an exercise of agency. In this sense, Ferrero holds, agency is 
"dialectically inescapable," or "closed under its own distinctive operation": one can only address the question whether there's reason to be an agent (or indeed, to do anything) while occupying the standpoint of agency itself (ibid.).

Suppose Ferrero is correct in thinking that any instance of giving and asking for reasons is, inescapably, an exercise of agency. (I raise doubts about this below, but let's suppose it for now.) It would follow that shmagents-by definition, non-agent beings - cannot request reasons to be an agent. But would this be an adequate response to Enoch's objection? It would, if the core of Enoch's objection were just that shmagents can request reasons to be an agent. And of course, it often does seem as if that's the core of Enoch's objection. However, I doubt that it ultimately is. In his (2011a) "Shmagency Revisited," Enoch seems to admit that focus on the figure of the shmagent, as someone raising the challenge, is in some ways misleading. Enoch's real concern is with the content of, and rationale for, the challenge itself, not with who or what kind of being raises it, if anyone.

To explain why, Enoch employs an analogy with a paperskeptical philosopher, who argues for the thesis that we shouldn't write philosophy papers (because doing so is intellectually corrupting, say). Curiously enough, the paperskeptical philosopher expresses her skeptical argument in a philosophy paper. There's a kind of performative selfcontradiction in doing so. What the paper-skeptical philosopher does isn't impossible, to be sure; but it's in a way incoherent. Still, Enoch thinks, if the paper-skeptic's arguments are sound, then the rest of us-and not just the paper-skeptic herself-are in trouble if we write philosophy papers. It's the content of her arguments that matters, not the fact that she (incoherently) raises them while writing a paper. We are not off the hook simply by pointing out that the paper-skeptic is being incoherent in raising her challenge to paper-writing. In a similar way, Enoch thinks, even if non- 
agents couldn't (coherently, or at all) raise the "why be an agent" question, understood as a request for reasons, it's the content and rationale of the request itself that matters, not who or what expresses it. Constitutivists are not off the hook simply by pointing out that the shmagent can't pose that question, or make that request. ${ }^{24}$

If that's right, then it's really just the question about reasons to "be an agent," and the putative rationale for it, that matter. To respond to Enoch's objection, it's not enough to show that a non-agent can't ask that question. In brief, I take it, Enoch's rationale for the request for reasons to "be an agent" was the analogy with other enterprises with constitutive standards: in the case of other such enterprises, we don't seem to have any reason to act in accord with those standards in the absence of prior reasons to engage in the enterprise. So one might think the same is true in the case of agency. If the challenge itself is good, then it's beside the point whether shmagents can issue the challenge, or whether it can be raised from a standpoint outside of agency. Even if Ferrero were right that shmagents can't issue the challenge, this wouldn't help constitutivism on its own.

Of course, as I already explained in $\$ 2$, the content and rationale for the challenge- - the request for reasons to be an agent-isn't really something that constitutivists ultimately need to worry about. Constitutivists just need to discharge the explanatory burden of showing how the constitutive standards of agency can ground reasons to act in accord with them, even in the absence of reasons to be an agent-an explanatory burden that, I argued, constitutivists face even without Enoch's objection. Enoch's objection thus poses no new hurdle for constitutivists. Still, we need this response to Enoch, rather than merely the idea that shmagents can't request reasons to be an agent.

\footnotetext{
${ }^{24}$ Enoch 2011a:218-220.
} 
Now, Ferrero does consider Enoch's appeal to the paperskeptic, but rejects it on the following grounds. First, Enoch himself makes ample use of the figure of the shmagent in originally presenting his objection, so one might well have thought that Enoch's point is precisely that shmagents can raise "external" challenges to the authority of agency's constitutive standards, by requesting reasons to be an agent. So it would be pertinent to show that they can't. Second, the case of the paper-skeptic is in any case irrelevant to the issue of "external" challenges to agency, for the paper-skeptic's challenge to paper-writing is "internal" - raised while writing a paper, or from within the practice of paper-writing. This may make it seem as if Enoch is now attempting to raise an analogous "internal" challenge to agency's constitutive standards. But while analogous "internal" challenges to agency can be raised - indeed it's a good question, according to Ferrero, whether there's a reason to be an agent that's available from within agency-Ferrero points out that Enoch gives us no reason to think that such "internal" challenges can't be met. ${ }^{25}$

I take Ferrero's points in turn. First, Ferrero is surely right that it often does seem as if Enoch's point is precisely that shmagents are possible, and that such beings could request reasons to be an agent. Still, I think we should also take Enoch at his word when he says, in re-addressing his shmagency challenge, that that isn't really his core objection; but rather, his core objection is about the content and rationale for the request for reasons to be an agent. Andcoming now to Ferrero's second point-if Enoch's core objection is just about the content and rationale of the request for reasons to be an agent, then again it doesn't matter whether anyone raises or makes this request-whether an agent or a shmagent. As I see it, Enoch isn't concerned even with the possibility of "internal" challenges to agency, in the

${ }^{25}$ Ferrero 2018, sections 4.1.-4.2; cf. section 7.2. 
sense of challenges raised from within agency, or while exercising agency. It doesn't matter whether the paperskeptical argument is raised in a paper, in a book, or just coalesces randomly in the sand thanks to a freak quantum event. It's the argument itself that matters, and that makes trouble for paper-writing if it's sound. Likewise, it doesn't matter whether anyone, whether an agent or a shmagent, raises the challenge about reasons to be an agent. It's the content and rationale of the challenge that matters, and that makes trouble for constitutivism if it stands.

Of course, again, I already argued in $\$ 2$ that the challenge doesn't stand: constitutivists don't really need to worry about reasons to "be an agent." My main point here is that, in focusing on whether shmagents (or even agents) can raise the request for reasons to be an agent, Ferrero doesn't go far enough in dismantling Enoch's objection. Whether shmagents or even agents can request reasons to be an agent is beside the point; to adequately address Enoch's objection, we have to attack the content of the request itself as misguided, as I did in $\$ 2$.

Finally, let me raise some doubts about whether Ferrero is correct in his claim that shmagents cannot request reasons to be an agent. A shmagent is a non-agent being. They don't perform actions, they don't act for reasons, and indeed have no use for practical reasons for anything. Still, it seems that such a being could be theoretically rational, and could grasp the concepts of an agent, of reasons for action and of normative reasons more broadly, and could be interested in philosophical questions about these concepts, and about the entities and properties to which those concepts apply. Further, it seems that such a theoretically rational being could entertain Enoch's argument, and become convinced that agency's constitutive standards at most inherit their authority from prior reasons to be an agent. Having become thus convinced, she might ask: what reason is there to be an agent? Is there such a reason? And like Enoch, she might 
worry that, even if there is a reason to be an agent, appeal to this reason would belie constitutivists' ambitions of giving the foundational account of where authoritative norms and reasons ultimately come from.

It's at least hard to see what's impossible about this scenario. More generally, I don't see why anyone needs to exercise agency in particular in understanding and appreciating Enoch's argument, and in thereby coming to ask whether there are reasons to be an agent. Even if agency is one activity that involves giving and asking for practical reasons, it needn't be the only such activity: philosophical reflection might involve it too. And philosophical argumentation and reflection is often thought of as the paradigm of contemplative, non-practical or merely theoretical rational activity. ${ }^{26}$ Of course, the shmagent-asphilosopher wouldn't herself have any use for practical reasons - including reasons to be an agent (assuming those are practical). Still, it seems that she can ask the question, perhaps being interested only in whether agents have reasons to be an agent.

So it seems that the shmagent-in particular, the shmagent-as-philosopher-can ask whether there are reasons to be an agent. Thankfully for the constitutivist, though, Ferrero is wrong to think that this spells trouble for constitutivism. Ferrero claims that to show that constitutivism is a "nonstarter," it would be "sufficient to show the intelligibility of raising the question about the reason to be an agent from outside of agency" (forthcoming, \$4.2). However, if constitutivists needn't worry about whether there are further reasons to be an agent, in order to ground reasons for action in agency-as I argued in $\$ 2$ then nor do they need to worry about whether it's intelligible or possible for someone, even a non-agent, to ask for such

${ }^{26}$ See e.g. Aristotle's Nicomachean Ethics, book X. 
further reasons. Even if the request is possible and intelligible, it's misguided.

\subsection{VELLEMAN}

There's a way of reading Velleman as giving a response to Enoch that's very similar to Ferrero's. ${ }^{27}$ In that case, similar retorts apply as those I just made in response to Ferrero. Even if it were impossible or unintelligible for a shmagent to request reasons to be an agent, this would be beside the point, for the core of Enoch's objection is about the content and rationale for the request for reasons to be an agent, not about whether someone can issue the request. On the other hand, it seems that shmagents can request reasons to be an agent; but this doesn't threaten constitutivism, since the request is misguided, as I argued in $\$ 2$.

However, there's also a slightly different way of reading Velleman. On this reading, Velleman argues that normative reasons for action or choice must be constitutivist; for the very concept of a reason for action or choice is the concept of a favorable evaluation by the lights of agency's constitutive standards. It would follow that, even if someone-say, a shmagent—can ask for reasons to be an agent, where these are understood as reasons to choose agency, they can at most ask for constitutivist reasons to be an agent. They cannot ask for non-constitutivist reasons to be an agent, simply because the very idea of such reasons is unintelligible. Accordingly, even if constitutivists need reasons to be an agent, they can rest assured that appeal to such reasons is consistent with constitutivists' foundational metanormative ambitions. And so long as there is a

27 Both Enoch (2011a:218-219) and Ferrero (2018, §3.3) read Velleman in this way. 
constitutivist reason to be an agent (and Velleman argues that there is $\left.{ }^{28}\right)$, constitutivism is safe.

Of course, I've already argued that the request for reasons to be an agent is misguided: constitutivists needn't worry about whether there are reasons to be an agent, or to choose agency, at all. So in a sense, constitutivists don't need Velleman's argument to point out that reasons to be an agent, or to choose agency, would have to be constitutivist reasons. Still, it's of independent interest if Velleman is correct that the very concept of a normative reason for action or choice is the concept of a favorable evaluation by the lights of agency's constitutive standards. For if that's the case, then unless our concept of a reason for action or choice is deeply erroneous, normative reasons for action or choice must be constitutivist. Velleman's response to Enoch thus doubles as a positive case for constitutivism. Unfortunately, as I'll now argue, that case is faulty.

Velleman's argument is formulated in terms of the shmagent's question "Why be an agent?" According to Velleman, in order to even grasp what the shmagent asks with this question, we must presuppose a criterion for what would count as a correct answer. Without a criterion, the question is incomplete or indeterminate, like the question "How does one win?"29 If you don't specify a game you're concerned with, we don't know what you're asking with "How does one win?" But if you do specify a game (say, chess or tennis) you thereby also specify the criteria for answering your question. These criteria are the constitutive standards of the game in question, since these standards define what it is to win at this game.

${ }^{28}$ Velleman 2009:138: the idea is that having and pursuing the aim of self-understanding itself serves the aim of self-understanding, so agency's constitutive aim supports its own pursuit.

29 Velleman 2000:176. His 2009:145 example is "Is a telephone correct rather than a tree?” Cf. Enoch 2011a:224-225. 
Velleman holds that the question "Why be an agent?" and indeed, any request for normative reasons for anything-behaves analogously. If the question "Why be an agent?" is precisified as the question "Why choose agency and its standards?", then the question is about what choice to make and why; and choices are moves within the "game" of agency. In this case, the question must be answered by appeal to agency's constitutive standards, just as the question "How does one win at chess?" must be answered by appeal to the constitutive standards of chess. Nothing else so much as makes sense. On the other hand, if the question is precisified as the question "Why shmoose agency and its standards?", then it's about what shmoice to make and why, where shmoices are moves within the "game" of shmagency (whatever shmagency and shmoice might be). Here the question would have to be answered by appeal to shmagency's constitutive standards, if it's intelligible at all. (Compare: "How does one win at tennis?") ${ }^{30}$

If Velleman is right, then it only makes sense to answer requests for normative reasons for action or choice by appeal to agency's constitutive standards. Velleman seems to concede that if there were such a thing as shmaction, distinct from action, for which we could have normative reasons, then requests for normative reasons for shmaction wouldn't be answerable by appeal to the constitutive standards of agency, but rather those of shmagency. Still, the only way it makes sense to answer requests for normative reasons for action or choice is by appeal to agency's constitutive standards. ${ }^{31}$

\footnotetext{
30 Velleman 2009:143.

31 One might object that this way of reading Velleman has him leaving unaddressed the question why we should worry about reasons for action rather than about reasons (or shmeasons) for shmaction. But surely it's fine for constitutivists to simply be
} 
This argument fails, however, for it begs the question at issue. Velleman merely assumes that in specifying that one is asking a question about why one should choose or act in a certain way, one settles it that the answer must be given by agency's constitutive standards. Of course, Velleman is right that if the "Why?" question is a request for normative reasons, then it's pertinent to ask: normative reasons for what? And it's one thing to ask for reasons for action, and another to ask for reasons for, say, belief, or for some other nonaction response. But it's a further and contentious claim that, if one asks why one should choose or act in accord with agency's constitutive standards-where this is request for reasons-only agency's constitutive standards themselves can answer this question. Indeed, this is just the claim at issue.

Moreover, even in the case of games such as chess, standards or considerations external to the game can clearly be relevant to how to play, and to whether to play at all. Even if only standards constitutive of a game are relevant to answering the question how to win at that game, other standards or considerations can be relevant to other questions about which moves in the game, if any, to make. (Indeed, this is part of Enoch's original point.) Suppose that, because of a betting arrangement, I'm likely to lose my home if I don't lose this game of chess. Here the consideration about keeping my home provides a criterion for which chess moves to make-and a criterion worth taking seriously. 32 The question whether and why one should make certain chess moves is not automatically settled by the constitutive standards of chess. Velleman gives no argument that

interested in reasons for action, as so many other theorists of practical reason are.

32 Of course I must also know which moves are bad qua chess moves, and this is determined by the rules of chess. 
questions about reasons for action or choice are more like the question how to win at chess, than they are like the question of which chess moves (if any) to make and why.

In sum, then, Velleman's argument fails to show that the very idea of a reason for action or choice is the idea of a favorable evaluation by the lights of agency's constitutive standards. Subsequently, the idea of non-constitutivist reasons for "choosing agency" still seems intelligible. ${ }^{33}$ This spells trouble for Velleman's response to Enoch (on my alternative reading of it). Of course, as I explained, this response isn't even needed: my response in $\$ 2$ suffices. Still, Velleman's argument was also of independent interest, as it looked like a positive way of arguing for constitutivism. Unfortunately, constitutivists need to keep looking for a better way.

\subsection{SILVERSTEIN}

Given the foregoing, we can discuss Silverstein's response to Enoch quite briefly. Like Ferrero, Silverstein disambiguates the shmagency challenge to an "external" request for reasons to be an agent, and an "internal" one. The "external" request is raised from "outside the standpoint of agency," such as that of shmagency; and the "internal" request is raised from "within the standpoint of agency" (2015:1133-4).

Silverstein then argues that the "external" request isn't intelligible. For if it's a request for reasons for the shmagent to choose agency, then it's unintelligible because it's "incomprehensible" to suggest that the shmagent, a being

${ }^{33}$ Compare Enoch 2011a:225-226, which might be read as arguing that the idea of non-constitutivist reasons seems intelligible, and that such appearances are strong evidence of semantic nondefectiveness of non-constitutivist senses of 'reason'. 
fundamentally incapable of choice, might nonetheless have reasons to choose (2015:1136). We might instead try to read the external request as a request for reasons for the shmagent to shmoose agency. But without an account of what shmagency and shmoice are, we have no good reason to think that this is an intelligible request, let alone that it voices a compelling normative question that constitutivists need to worry about (2015:1136-7).

On the other hand, the "internal" request is intelligible, and often compelling: agents often face compelling questions about whether they should be, or remain, agents, or instead relinquish their agency, for example by sacrificing themselves for the sake of others. Furthermore, perhaps agency's constitutive standards don't always recommend remaining an agent: they might sometimes recommend exiting agency instead. Still, Silverstein argues that this poses no threat to the authority of agency's constitutive standards. For since "internal" requests for reasons are issued from within the "standpoint of agency," we can rest assured that the correct answers to such requests, whatever they are, are dictated by agency's constitutive standards (2015:1134-6).

In response, start with Silverstein's last point. The mere fact that a request for reasons to be an agent is an "internal" one, so that one seeks an answer to it through exercising agency, doesn't show that the correct answer to it must be given by agency's constitutive standards. It certainly seems as if other, external standards or considerations might be relevant to the question of whether and why to choose agency. This is similar to how, in Velleman's case, the mere fact that one was seeking an answer to a question about whether, why or how to exercise one's agency, didn't show that the correct answer must be given by agency's constitutive standards. What about the external request for reasons to be an agent? Silverstein might be right that shmagents can't themselves have reasons to choose agency, for they are incapable of choice at all. Still, for reasons already 
spelled out in \$3.1, it seems that shmagents can intelligibly ask about whether agents have reasons to choose agency. In this sense, a version of the "external" request for reasons to be an agent is intelligible.

Of course, I ultimately agree with Silverstein that neither the external nor the internal request for reasons to be an agent spells trouble for constitutivism. But the reasons why I think this are importantly different from Silverstein's. Once again, even if (a version of) the shmagent's external request for reasons to be an agent is intelligible, it's misguided. We haven't seen any good argument for thinking that, in order for constitutivists to be able to ground reasons for action in agency, there must also be some further reason to "be an agent." For similar reasons, neither does the internal request for reasons pose a problem for constitutivism. It's not that such internal requests are, just in virtue of being requests made through exercising agency, guaranteed to be appropriately answered only by appeal to agency's constitutive standards. I don't see why they would be. Rather, the internal request isn't problematic because, again, even if (or when) there's no reason to "be an agent," the constitutivist's account of the reasons that there are might still be in good order.

\subsection{SMITH, AND LOOKING FORWARD}

I've been discussing perhaps the most prominent strand in previous responses to Enoch: the idea that the "external" shmagency challenge isn't even possible or intelligible, and that this somehow dismantles Enoch's objection; whereas the "internal" challenge can be handled by the constitutivist - or at least, that Enoch gives us no good argument to show that it can't. As I've explained, I think this strand of responses involves various confusions, and in any case doesn't get to the heart of either Enoch's objection or 
what's wrong with it. Enoch's objection isn't about the standpoint from which the request for reasons to be an agent can be raised, and doesn't depend on (the possibility of) anyone's raising it. But nor do constitutivists need to worry about the request for reasons to be an agent, for their positive project doesn't depend on the availability of such reasons.

While I thus think that this prominent strand of responses to Enoch is importantly mistaken, I've discussed it at some length partly because the "shmagency" wars have been raging for over a decade now, and I think the debate needs a change of course. If I'm right, then Enoch's objection ultimately poses no good challenge to constitutivism that it doesn't face anyway: constitutivists must show how to ground reasons for action in agency's constitutive standards - which is just their positive project. If the project succeeds, constitutivists would thereby also show that agency's constitutive standards don't merely inherit their authority from some explanatorily prior normative reasons to heed them, but rather, are authoritative in and of themselves, simply because, and in the sense that, agency's constitutive standards ground normative reasons for agents to do what it's good by the lights of those very standards to do. The success of this positive constitutivist project doesn't depend on the intelligibility or possibility of the shmagent's requesting reasons to be an agent, any more than it depends on whether there are any reasons to be an agent. We should thus redirect the debate over constitutivism's metanormative ambitions away from these latter questions, and towards the straightforward question of precisely how the constitutivist grounding of reasons for action in the standards of agency is supposed to go. ${ }^{34}$

34 There are of course also other, different objections to constitutivism's metanormative ambitions than Enoch's shmagency objection. For example, Tiffany 2012 and Tubert 2011 
The person who comes closest to clearly articulating the need for this course correction in the shmagency debates is Michael Smith. ${ }^{35}$ He writes that he has "demonstrated that it's possible" to derive reasons from agency "by actually providing such a derivation" (2015:199). In brief, Smith argues that it's analytic that an agent has a reason to act in a certain way "just in case her acting in that way brings about an outcome that is desirable-relative-to-her" (2015:198). Further, he argues that it's analytic that "an outcome is desirable-relative-to-[an agent] just in case that outcome is desired by her ideal counterpart" (ibid.); and that it's analytic that the relevant "ideal counterpart is her optimally functioning counterpart qua agent"- that is, a counterpart that performs the function of agency, or satisfies the constitutive standards of agency, optimally well (ibid.). If Smith is right about all this - and of course I haven't here provided his actual arguments-it would follow that an agent has a reason to act in a certain way just in case her acting in that way brings about an outcome that her ideally functioning counterpart qua agent would desire. That is, facts about the desires of the agent's ideal-qua-agent counterpart fix the facts about what the agent has reason to do. Of course, this falls strictly short of claiming that these facts

argue that to be plausible, constitutivist conceptions of agency must be rather thin, but deriving a compelling substantive account of reasons for action requires leaning on a much thicker and more controversial account of agency. This objection might still be a good one, for all I say here, even if Enoch's objection isn't.

35 O'Hagan 2014:23 also gives some hints of this, when she writes that "it would be question-begging to suppose that the only method for demonstrating that the constitutive aims of agency are not normatively arbitrary is by appeal to a regress-stopping reason to be an agent." However, O'Hagan doesn't develop this suggestion very clearly, and mostly her discussion is couched in terms similar to those I've been criticizing. 
about ideal-qua-agent counterparts' desires ground agents' reasons for action. Still, where there's necessary covariation between facts about reasons and facts about the desires of ideal-qua-agent counterparts, we should ask what explains that covariation. And at least one good hypothesis is that facts about agents' reasons are grounded in facts about the desires of their ideal-qua-agent counterparts.

Armed with his positive constitutivist account of reasons, Smith's response to the question whether someone should be an agent, or has reasons to be an agent, is that it depends: Smith's own constitutivist account has the consequence that sometimes one shouldn't be (or remain) an agent. In particular, because Smith holds that optimally functioning agents have specific coherence-inducing desires that dispose one towards recognizably pro-moral actions (2015:190-192), and because there might be circumstances in which such actions include self-sacrifice for the sake of others (2015:196), it follows that there might well be circumstances in which one shouldn't be (or remain) an agent. Still, this doesn't seem like an objection to the constitutivist account, but merely a consequence of it (2015:196).

I think that, in a way, Smith's overall strategy here is exactly right. However, without my explanation in $\$ 2$ of why the success of constitutivist attempts to ground reasons in agency doesn't in general depend on whether there's also reason to be an agent, Enoch might well find Smith to be too unresponsive to his objection. In particular, Enoch might complain that Smith isn't licensed to ignore the objection on the way to the conclusion that his constitutivist account does succeed in grounding reasons, and then later lean on that constitutivist account to address the objection: that would put the cart before the horse. Whatever the case may be, I hope that my argument in $\$ 2$ enables us to clearly see that constitutivists indeed can—and should—offer their positive accounts of reasons for action, as Smith does, 
without therein worrying about the request for reasons to be an agent.

\section{HOW TO GROUND REASONS FOR ACTION IN THE CONSTITUTIVE STANDARDS OF AGENCY: A SKETCH}

\$3.4 very briefly sketched Smith’s positive constitutivist account of reasons. For all I say here, Smith's arguments in favor of that account might or might not succeed. ${ }^{36} \mathrm{I}$ offer the following as an alternative skeleton for developing a positive constitutivist account, an alternative that seems to me worth taking seriously.

Start with the idea, familiar from $\$ 1$, that we can ground attributive evaluations of exercises of agency in facts about agency's constitutive standards, via Attributive Goodness. Exercises of agency are better (worse) qua such exercises the better (worse) they conform to or satisfy agency's constitutive standards. (Enoch didn't dispute this idea.) The strategy I recommend is to link such attributive evaluations with normative reasons for action, via two main steps; and to use this link to argue that reasons are defined in terms of such attributive evaluations.

The first step is to defend a conceptual connection between normative reasons for action and good practical deliberation; in particular, deliberation that is good tout court, all told-where we don't assume that this amounts to deliberation that is good qua exercise of agency. The rough idea is that normative reasons for action are considerations that good practical deliberation takes into account; and that when the reasons are decisive, it's part of good deliberation to act on those reasons, in the way that the reasons support. This "Deliberative Constraint" on reasons is relatively

\footnotetext{
36 Though see Bukoski 2016 for forceful objections.
} 
orthodox, and has seemed even platitudinous to some. ${ }^{37} \mathrm{It}$ captures the commonsense idea that, in order to make good decisions, decisions that are supported by normative reasons, we should take those reasons into account rather than ignoring them. While the Deliberative Constraint hasn't gone unchallenged, ${ }^{38}$ it is highly plausible, relied upon often even if only implicitly, ${ }^{39}$ acceptable for even those who aren't constitutivists, and-while I cannot support this herebacked up by good positive arguments..$^{40}$

The second and more controversial step is to argue that, given certain premises about the nature of agency, the best hypothesis concerning what deliberating well tout court consists in is that it just is deliberating well qua agent. That is, good deliberation of the sort that figures in the Deliberative Constraint-deliberation that involves taking into account our normative reasons, and acting on them in the ways that they support-just is deliberation that is good by the lights of the constitutive standards of agency. I consider briefly below how one might support this step. For now, let's see how it would help the constitutivist.

It would follow from the Deliberative Constraint, together with the identification of deliberation that is good

37 See e.g. Setiya 2014:221, 223; Way 2017:1; Schroeder 2007:26, 33, 130, 136-40; Raz 1978:5 and 1999b:228; Darwall 1983:30-31; Horty 2012.

38 See esp. Markovits 2014:41, 47-8; Smith 2009; 523; and Schroeder 2007:33. Since Smith challenges and ultimately rejects the Deliberative Constraint, this is one key way in which my proposed way of grounding reasons in agency differs from his.

${ }^{39}$ For examples of such reliance, particularly by non-constitutivists, see e.g. Horty 2012, Williams 1981, McDowell 1995, Way 2017, Setiya 2014, 2007.

${ }^{40}$ For such positive arguments, as well as a response to the central challenges to the Deliberative Constraint, see Paakkunainen 2017b. 
tout court with deliberation that is good qua exercise of agency, that normative reasons for action are considerations that deliberation that is good qua exercise of agency takes into account; and if the reasons are decisive, leads to action on. In other words, there would be a striking necessary covariance between facts about which considerations, $p$, are normative reasons for what, and facts about which considerations, $p$, one would take into account and act on (and how) if one deliberated well qua agent. As before, where there's a necessary covariance, it's a good question what might explain it. The covariance on its own is, of course, compatible with the non-constitutivist "tracking" hypothesis that it's in the nature of agency to respond to independently existing normative reasons, and that goodness qua agent is a matter of the accuracy of one's response. However, constitutivists purport to give an account of agency and its constitutive standards that is not of this "tracking" sort, but is prior to any claims about normative reasons. Assuming that they can successfully give such an account of agency, the best explanation of why facts about deliberating well qua agent so tightly constrain facts about reasons seems to be that reasons are defined in terms of agency, not vice versa: what it is to be a reason for action just is to be a premise in deliberation that is good qua exercise of agency. ${ }^{41}$ This is how constitutivists can in principle ground facts about which considerations are normative reasons for which actions in

41 Alternatively, perhaps some third factor explains the coincidence. Perhaps a deity harmonized the constitution of agents with facts about reasons, though neither is grounded in the other. I leave it as further work for constitutivists to argue against such views, or else to assume them away by assuming a broad philosophical naturalism. A yet further option is ontological interdependence: while reasons are defined in terms of agency, agency is also defined in terms of reasons (cf. Wedgwood 2007). I don't count such views about agency as "constitutivist" here. 
facts about the constitutive standards of agency-provided their accounts of agency are of the right sort.

That would be nice if it worked. But why believe that deliberation that is good tout court just is deliberation that is good qua exercise of agency? Compare: deliberating well qua a jewel thief-weighing considerations and acting on them in the way characteristic of good jewel thieves-plausibly diverges significantly from deliberating well tout court, where the latter is a matter of taking into account, and acting on, genuine normative reasons. For plausibly we don't generally have normative reasons to act as good jewel thieves act, or on the considerations that they would take to be relevant or weighty. What, then, is special about agency and its constitutive standards, such that there isn't an analogous gap between deliberating well tout court and deliberating well qua agent? Constitutivists must eliminate this threatening gap. ${ }^{42}$

I can here only sketch a strategy for closing the threatening gap. The obvious strategy would be to argue for an account of agency and its constitutive standards on which the contours of deliberating well qua agent turn out to match our most important intuitive judgments about what normative reasons people have. If a given view about agency's constitutive standards delivers verdicts about what deliberating well qua agent looks like that strikingly correspond to our intuitive verdicts about normative reasons-so that deliberating well qua agent involves giving just the right weight to just the right considerations in deliberation-this would be good evidence for the constitutivist's identification of deliberation that is good tout court with deliberation that is good qua exercise of agency.

42 Of course, the concerns raised here are very similar to those fueling Enoch's shmagency objection. Still, if my arguments in this paper are correct, Enoch hasn't given any good positive argument for thinking that such concerns can't be overcome by the constitutivist's positive account. 
For again, the striking alignment wouldn't likely be a sheer accident. Supposing the constitutivist's view of agency and its constitutive standards is not merely gerrymandered to accommodate the correct normative verdicts, but is wellsupported on independent grounds-grounds having to do with the conditions of agency - the best explanation for the striking alignment seems to be the sought-after identification.

There's of course much, much more work to do if we wish to develop this skeleton proposal into a full constitutivist view. But importantly, the most difficult remaining questions for the proposal seem to concern whether constitutivist accounts of agency turn out to be, without gerrymandering, all that the proposal needs them to be. Given such accounts of agency, it seems that the normative rabbit could be pulled out of the agential hat. In any case, I hope the proposal gives us at least some sense of precisely how constitutivists could ground reasons for action in facts about the constitutive standards of agency, even in the absence of reasons to "be an agent." No appeal to reasons to be an agent is involved in the skeleton proposal, and the difficult questions that remain for the proposal don't require appeal to such reasons either.

\section{CONCLUSION}

I've argued that the request for reasons to "be an agent" that is central to Enoch's famous "shmagency" objection is misguided. The success of the constitutivist project of grounding normative reasons for action in facts about the constitutive standards of agency doesn't turn on whether there are, in addition, reasons to be an agent. ${ }^{43}$ Relatedly, I

\footnotetext{
43 I recently found out that David Horst's (ms) "In Defense of Constitutivism about Epistemic Normativity" argues for a similar
} 
explained why a central strand of argument in previous responses to Enoch has gone awry. Many extant discussions focus on the question whether the request for reasons to be an agent is even possible or intelligible-specifically, whether it can be intelligibly raised from a perspective outside of agency (such as that of "shmagency"). As I argued, even if the request for reasons to be an agent is intelligible, and can be intelligibly made by some non-agent being, this isn't a problem for constitutivism. Since it doesn't matter for constitutivism's prospects whether there are reasons to be an agent, neither does it matter if the request for such reasonswhatever perspective it's launched from-is possible or intelligible.

I have thus sought to move the debate about constitutivism's metanormative ambitions away from such questions about whether certain challenges can be intelligibly launched, and from what perspective they can be launched, and towards the straightforward question of precisely how the constitutivist's positive grounding of reasons in agencysans reasons to "be an agent"-is supposed to go. I closed by briefly sketching a way in which such a grounding would succeed, provided certain assumptions about the nature of agency. Apart from providing an (outline) alternative to accounts developed in more depth by e.g. Michael Smith, ${ }^{44}$ I

conclusion concerning constitutivism about epistemic normativity: no prior and independent reasons for heeding the constitutive standards of belief are needed in order for these standards to have reason-giving force. Though Horst's arguments are quite different from mine, our projects have obvious affinities.

44 There are of course other alternatives styles of constitutivist metanormative argument, besides Smith's or mine. See e.g. Katsafanas 2013, 2018 (mentioned in n.19 above); and Korsgaard 1996, 2009. Further, aside from the above-mentioned reading of Velleman (in \$3.2.), we might read Velleman as arguing for constitutivism on the basis of Williamsian (1981) "internalism," the view that $p$ is a reason for A to $\Phi$ only if $p$ indicates that $\Phi$-ing 
hope the sketch also helps in seeing even more clearly why the success of the constitutivist project of grounding reasons in agency doesn't depend on the question whether there's reason to "be an agent." 45

serves a pre-existing motive of A's; together with the view that certain pre-existing motives (such as the drive for selfunderstanding) are necessary for agents as such. Velleman clearly accepts such Williamsian internalism (2009:118-120); though as Enoch (2011a:217) notes, the path from internalism to constitutivism is fraught.

${ }^{45}$ For very helpful feedback on previous versions, precursors, or parts of this paper, I'm grateful to Daniel Star, Paul Katsafanas, and the other participants in the Boston University Ethics Reading Group in April 2012; to Bill FitzPatrick, Terence Cuneo, and the audience in the Feb 2014 Central APA Symposium "Can Normativity Be Naturalized?"; to Daniel Wodak, Adam Lerner, Michael Smith, and the other participants in the Princeton Workshop in Normative Philosophy in March 2014; and to Kathryn Lindeman, Kieran Setiya, David Horst, and three anonymous referees. 


\section{REFERENCES}

ARISTOTLE, Nicomachean Ethics. Transl. Christopher Rowe, with Philosophical Introduction and Commentary by Sarah Broadie. Oxford: Oxford University Press, 2002.

BukOsKI, M. A Critique of Smith's Constitutivism. Ethics 127(1):116-146, 2016.

DARWALL, S. Impartial Reason. Ithaca: Cornell University Press, 1983.

DreIER, J. 1997. Humean Doubts about the Practical Justification of Morality. In Ethics and Practical Reason, eds. Cullity \& Gaut. Oxford: Clarendon Press, 1997. Reprinted with some modifications in Millgram, ed. 2001. Varieties of Practical Reasoning. Cambridge, MA: MIT Press.

ENOCH, D. Agency, Shmagency: Why Normativity Won't Come from What is Constitutive of Action. The Philosophical Review 115: 169-198, 2006.

Shmagency Revisited. In New Waves in Metaetbics, ed. Michael Brady. Palgrave: MacMillan, 2011a.

Taking Morality Seriously: A Defense of Robust Realism. Oxford: Oxford University Press, 2011b.

FERrERO, L. Constitutivism and the Inescapability of Agency. In Oxford Studies in Metaethics, Vol. 4. Ed. Russ Shafer-Landau. Oxford: Oxford University Press, 2009.

FERRERO, L. Forthcoming. Inescapability Revisited. Manuscrito, 2018.

GEACH, P. Good and Evil. Analysis 17:32-42, 1956. 
HORTY, J. Reasons as Defaults. Oxford: Oxford University Press, 2012.

Horst, D. (ms). In Defense of Constitutivism about Epistemic Normativity.

Katsafanas, P. Agency and the Foundations of Ethics: Nietzschean Constitutivism. Oxford: Oxford University Press, 2013.

Constitutivism and Practical Reason. In The Oxford Handbook of Reasons and Normativity, ed. Daniel Star. Oxford: Oxford University Press, 2018.

Kornblith, H. Belief in the Face of Controversy. In Feldman, R. \& Warfield, T. A. (eds.) Disagreement. Oxford: Oxford University Press, 2010, pp.28-52.

KorsgaArD, C. M. The Sources of Normativity. Cambridge: Cambridge University Press, 1996.

Self-Constitution: Agency, Identity, and Integrity. Oxford: Oxford University Press, 2009.

LINDEMAN, K. Constitutivism without Normative Thresholds. Journal of Ethics and Social Philosophy 12(3):231-258, 2017.

Markovits, J. Moral Reason. Oxford: Oxford University Press, 2014.

MCDowelL, J. Might There Be External Reasons? In J.E.J. Altham and Ross Harrison, eds. World, Mind, and Ethics. Cambridge: Cambridge University Press, 1995.

O'HAGAN, E. Shmagents, Realism and Constitutivism about Rational Norms. The Journal of V alue Inquiry 48(1):1731, 2014.

PAAKKunAinen, H. Normativity and Agency. In Routledge Handbook of Metaetbics, ed. Tristram McPherson \& David Plunkett. Routledge, 2017a. 
Can There Be Government House Reasons for Action? Journal of Ethics \& Social Philosophy 12:56-93, 2017b.

2018. The "Just Too Different" Objection to Normative Naturalism. Philosophy Compass 13:e12473. https://doi.org/10.1111/phc3.12473

RAZ, J, ed. Practical Reasoning. Oxford: Oxford University Press, 1978.

Agency, Reason, and the Good. In Raz, J. Engaging Reason: On the Theory of Value and Action. Oxford: Oxford University Press, 1999a.

The Truth in Particularism. In Raz, J. Engaging Reason: On the Theory of Value and Action. Oxford: Oxford University Press, 1999b.

Rosati, C. Agency and the Open Question Argument. Ethics 113:490-527, 2003.

Agents and "Shmagents": An Essay on Agency and Normativity. Oxford Studies in Metaethics Vol. 11:182213, 2016.

Schroeder, M. Slaves of the Passions. Oxford: Oxford University Press, 2007.

Setiya, K. Reasons without Rationalism. Princeton: Princeton University Press, 2007.

What Is a Reason to Act? Philosophical Studies 167:221235, 2014.

SilversteIN, M. The Shmagency Question. Philosophical Studies 172:1127-1142, 2015.

Smith, M. Reasons With Rationalism After All. Analysis 69 No.3: 521-30, 2009. 
A Constitutivist Theory of Reasons: Its Promise and Parts. Law, Ethics, and Philosophy 1:9-30, 2013.

The Magic of Constitutivism. American Philosophical Quarterly 52:187-200, 2015.

TIFfany, E. Why Be an Agent? Australasian Journal of Philosophy 90(2):223-33, 2012.

Tubert, A. Korsgaard's Constitutive Arguments and the Principles of Practical Reason. Philosophical Quarterly 61: 343-62, 2011.

Velleman, J. D. The Possibility of Practical Reason. Oxford: Oxford University Press, 2000.

How We Get Along. Cambridge: Cambridge University Press, 2009.

Vogler, C. Reasonably Vicious. Cambridge, MA: Harvard University Press, 2002.

WALDEN, K. Laws of Nature, Laws of Freedom, and the Social Construction of Normativity. In Russ ShaferLandau, ed. Oxford Studies in Metaethics 7:37-79, 2012.

WAy, J. Reasons as Premises of Good Reasoning. Pacific Philosophical Quarterly 98(2):1-20, 2017.

WedgwoOd, R. The Nature of Normativity. Oxford: Oxford University Press, 2007.

WiLliams, B. Internal and External Reasons. In Williams, Moral Luck. Cambridge: Cambridge University Press, 1981.

\section{$(c c)$ EY}

